\title{
Quasicrystalline Powders as the Fillers for Polymer-Based Composites: Production, Introduction to Polymer Matrix, Properties
}

\author{
A.A. Stepashkin, D.I. Chukov, L.K. Olifirov, A.I. Salimon \\ and V.V. Tcherdyntsev
}

\begin{abstract}
Powders of icosahedral $\mathrm{Al}_{65} \mathrm{Cu}_{23} \mathrm{Fe}_{12}$ and decagonal $\mathrm{Al}_{73} \mathrm{Cu}_{11} \mathrm{Cr}_{16}$ quasicrystalline intermetallics were synthesized by the mechanical alloying in combination with subsequent annealing. The conditions of mechanical alloying were purposely chosen to obtain the composite materials filled by dispersed $(<3 \mu \mathrm{m})$ quasicrystalline particles. A number of silanes were tested for the surface treatment of quasicrystalline particles in order to provide the uniform distribution of quasicrystals over the polymer melt and chemical binding with the polymer matrix and the most efficient silane type was found. The composites based on ethylene-vinyl acetate EVA, polysulphone PSU, and polyphenylene sulfide PPS were produced by the filling with quasicrystalline powders. The study of rheological characteristics has shown that high fluidity of the melt is retained, while uniform distribution of quasicrystalline particles over the polymer is provided. The data of mechanical and physical properties are reported.
\end{abstract}

Keywords Quasicrystals • Composite materials • Mechanical alloying Silane $\cdot$ Extrusion $\cdot$ Wettability

\footnotetext{
A.A. Stepashkin · D.I. Chukov $(\bowtie) \cdot$ L.K. Olifirov · A.I. Salimon · V.V. Tcherdyntsev National University of Science and Technology "MISIS", Bld 4, Leninsky prospect, Moscow, Russia e-mail: dil_chukov@mail.ru

A.A. Stepashkin

e-mail: a.stepashkin@misis.ru

A.I. Salimon

e-mail: a.stepashkin@misis.ru

V.V. Tcherdyntsev

e-mail: vvch@misis.ru

(C) The Author(s) 2018 


\section{Introduction}

In spite of expectations based mainly on scientific intuition and more than 30 years of fundamental studies worldwide quasicrystals (QC) have not found the applications at industrial scale. In general, the quasicrystals possess the combination of some attractive properties for general uses: high hardness and wear resistance, low surface energy, low friction coefficient, significant radiation and corrosion resistance, low electrical and thermal conductivity, and unusual optical properties [1-7]. Possible areas of application of an unusual combination of thermal, electrical, and optical properties of quasicrystals were considered in [4, 7-12]. The QC phases can be used as wear-resistant, heat-shielding coatings operating at the temperatures above $450-600{ }^{\circ} \mathrm{C}$. Recent discovery of superplasticity in the nanoscaled single quasicrystals [13] may provoke a fresh start in the search of commercially promising structural applications, since their intrinsic brittleness is considered as the main obstacle for processing, shaping and final use as the bulk product.

The application of quasicrystals in the form of powders and namely as the fillers for composites rests, perhaps, the only option for further development of structural materials which utilize the quasicrystalline form of matter. Al matrix composites reinforced with Al based quasicrystals [14-22] have demonstrated merely good combination of mechanical and tribological properties, although still far from the best conventional precipitation hardened $\mathrm{Al}$ alloys or $\mathrm{Al}$-ceramics composites. The polymer-based composites filled with powder quasicrystalline fillers seem to be much more promising since they simultaneously improve physical, mechanical, tribological and thermal properties [23-27]. The development of these composites, besides the proper characterization, presumes the solution of a number of engineering problems: mass production of quasicrystalline powders, search for the suitable binding agents and the optimization of the filler content in order to remain the processability with the highly productive technologies. This article reports and discusses the recent progress reached along this methodology pass.

\section{Experimental}

Pure Al, $\mathrm{Cu}, \mathrm{Fe}$, and $\mathrm{Cr}(98.5-99.5$ at.\%) powders (d50 about $498 \mu \mathrm{m}$ for $\mathrm{Al}$ and d50 about $35 \mu \mathrm{m}$ for others) were used for the mechanical alloying (MA) of $\mathrm{Al}_{65} \mathrm{Cu}_{23} \mathrm{Fe}_{12}$ and $\mathrm{Al}_{73} \mathrm{Cu}_{11} \mathrm{Cr}_{16}$ compositions (in at.\%) by means of water-cooled APF-3 planetary ball mill. The time of MA varied from 20 to $180 \mathrm{~min}$. Loading and unloading of the powders into the vials was provided in an inert atmosphere (argon gas). Pure ethanol was used as process control agents (PCA) to prevent cold welding of powder particles to each other and to the walls of the vials and balls. The annealing of the powders obtained by mechanical alloying (precursors of the quasicrystals) was performed in a pure argon atmosphere, at the temperatures of about $600-800{ }^{\circ} \mathrm{C}$. 
Surface treatment of the obtained quasicrystalline powders was carried out using following silanes: triethoxyvinylsilane Geniosil GF 56, gammamethacryloxypropyltrimethoxysilane Silquest A-174, and polydimethylsiloxane PDMS 200. Silanization of the quasicrystalline fillers was performed in $20 \%$ ethanol solution at a temperature of $40-45{ }^{\circ} \mathrm{C}$ for $6 \mathrm{~h}$ under intensive stirring.

Ethylene-vinyl acetate Evatane 28-05 and Evatane 28-40 (Arkema), PPS (DIC DSP B-100-C) and PSU (Ultrason S2010) were used as the polymer matrix.

$\mathrm{X}$-ray diffraction analysis was performed using an automated X-ray diffractometer DRON-4-07, with $\mathrm{CoK} \alpha$ monochromatic radiation. The spectra were analyzed using reduced Rietweld refinement.

The "thermoplastic polymer-quasicrystal" concentrates were prepared by the extrusion using Thermo Scientific HaakeMiniLab and Scientific LTE-16 laboratory extruders. The degree of granulate filling with the quasicrystals was about 10-40 wt $\%$. The mixing procedure was performed at the temperatures of about $110-130{ }^{\circ} \mathrm{C}$, in a HaakeMiniLab Thermo Scientific extruder. The time of the mixing was varied in the range from 3 to $15 \mathrm{~min}$. The resulting melt flow of concentrates was measured with a CEAST MFT7025 rheometer, in accordance with ISO 1133: 2011 [Plastics-Determination of the melt mass-flow rate (MFR) and the melt volume-flow rate (MVR) of thermoplastics]. The measurements were carried out at a temperature of $190{ }^{\circ} \mathrm{C}$ for the following set of loads: $1.2-2.16-3.8-5 \mathrm{~kg}$.

The microstructure of the samples of the powder compositions and polymer concentrates was examined with Hitachi TM-1000 and Tescan Vega3 scanning electron microscopes. The microstructure of the concentrates was studied on the chips made in liquid nitrogen.

The FTIR spectroscopy of the thermoplastic polymer-quasicrystals concentrates was performed using a Nicolet $380 \mathrm{IR}$-Fourier spectrometer (the spectral range of $4000-450 \mathrm{~cm}^{-1}$ with a resolution of about $0.9 \mathrm{~cm}^{-1}$, the accuracy of the wave number of $0.01 \mathrm{~cm}^{-1}$ ) in attenuated total reflection (ATR) mode.

\section{Results and Discussion}

Figure 1 summarizes the data on the phase composition of the mechanically alloyed powder mixtures after the annealing at the temperatures varying over range 25$900{ }^{\circ} \mathrm{C}$. The quasicrystalline intermetallics are formed due to the solid state reactions and their content can reach up $90 \%$ after the annealing at $700-750{ }^{\circ} \mathrm{C}$ in the $\mathrm{Al}-\mathrm{Cu}-\mathrm{Fe}$ system and at $850-900{ }^{\circ} \mathrm{C}$ in the $\mathrm{Al}-\mathrm{Cu}-\mathrm{Cr}$. This provides the mass production of quasicrystalline powder fillers and potentially mechanical alloying as the technology may recycle the debris, chips, and other rests of machining to reduce the costs for composite materials. The optimal powder fillers' size to reinforce the thermoplastic polymers is achieved by annealing at $700-800{ }^{\circ} \mathrm{C}$. It consists of weakly bound agglomerates of quasicrystalline particles with the thickness of about $20-30 \mu \mathrm{m}$ and length size of about $300-400 \mu \mathrm{m}$, whereas the individual particles are $1-3 \mu \mathrm{m}$ in size - see Fig. 2. During the extrusion mixing under the action of 

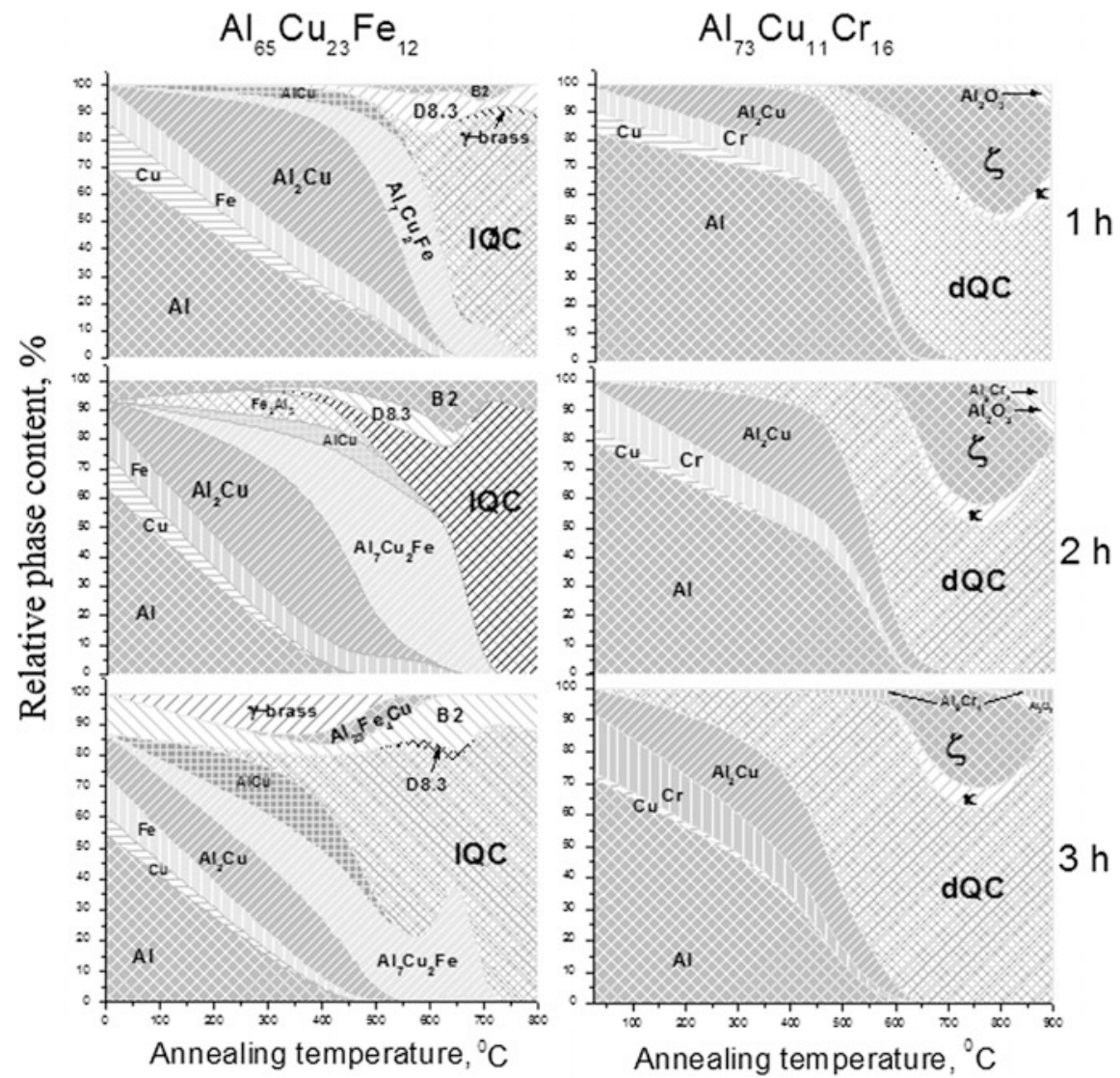

Fig. 1 Evolution of phase compositions of as-milled powders after annealing (IQC icosahedral quasicrystalline phase, $d Q C$ decagonal quasicrystalline phase, $D 8.3 \mathrm{Al}_{4} \mathrm{Cu}_{9}, B 2 \mathrm{AlFe}, \gamma$ brass $\left.\mathrm{Al}_{17} \mathrm{Cu}_{33}, \zeta \mathrm{Al}_{72.3} \mathrm{Cu}_{10.9} \mathrm{Cr}_{16.8}, \kappa \mathrm{Al}_{67.4} \mathrm{Cu}_{14.3} \mathrm{Cr}_{18.3}\right)$

shear, these agglomerates decompose into individual particles and are distributed over the polymer.

Figure 3 shows the FTIR spectra of the $\mathrm{Al}_{65} \mathrm{Cu}_{23} \mathrm{Fe}_{12}$ quasicrystalline powders treated with silanes (observed spectra of icosahedral $\mathrm{Al}_{65} \mathrm{Cu}_{23} \mathrm{Fe}_{12}$ phase and decagonal $\mathrm{Al}_{73} \mathrm{Cu}_{11} \mathrm{Cr}_{16}$ phase treated by silanes are identical). The absorption at $790 \mathrm{~cm}^{-1}$ associated with Al-O symmetric stretching, the broad absorption at $1200-900 \mathrm{~cm}^{-1}$ range associated with $\mathrm{Al}-\mathrm{O}-\mathrm{Si}$ and $\mathrm{Si}-\mathrm{O}-\mathrm{Si}$ bonds and the absorption at $930-970 \mathrm{~cm}^{-1}$ associated $\mathrm{Al}-\mathrm{OH}$ bond were revealed. This confirms the fact that the bond with the silane is carried out through the interaction with $\mathrm{Al}$ mainly and the formation of $\mathrm{Al}^{3+}$ ions. The strongest line of asymmetric stretching vibration of Al-O-Si and $\mathrm{Si}-\mathrm{O}-\mathrm{Si}$ is observed in the case of Geniosil GF 56. In the case of silane Silquest A174, the peaks, which are characteristic to silane, remain, but their weaker intensity reflects the weaker interaction between silane and 

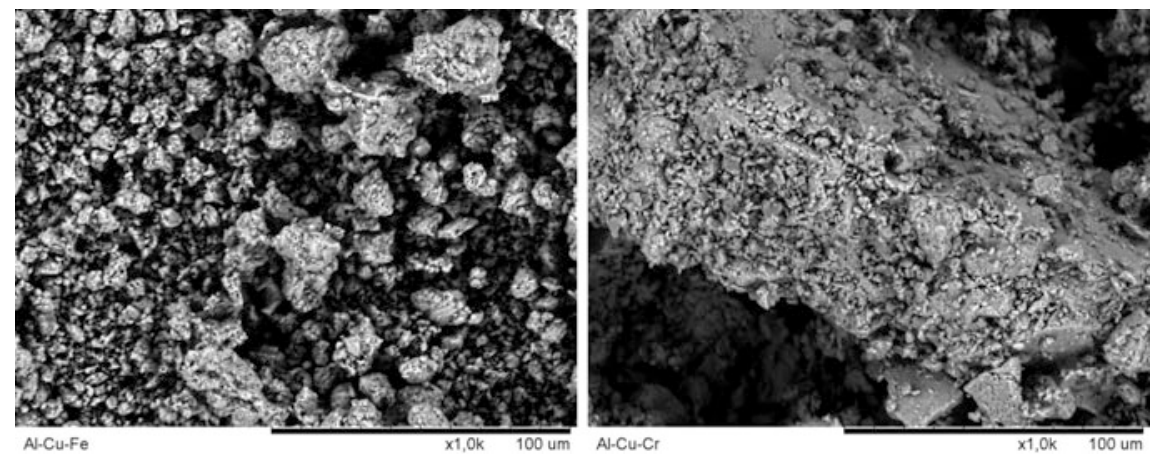

Fig. 2 The appearance of mechanically alloyed and annealed quasicrystalline powders
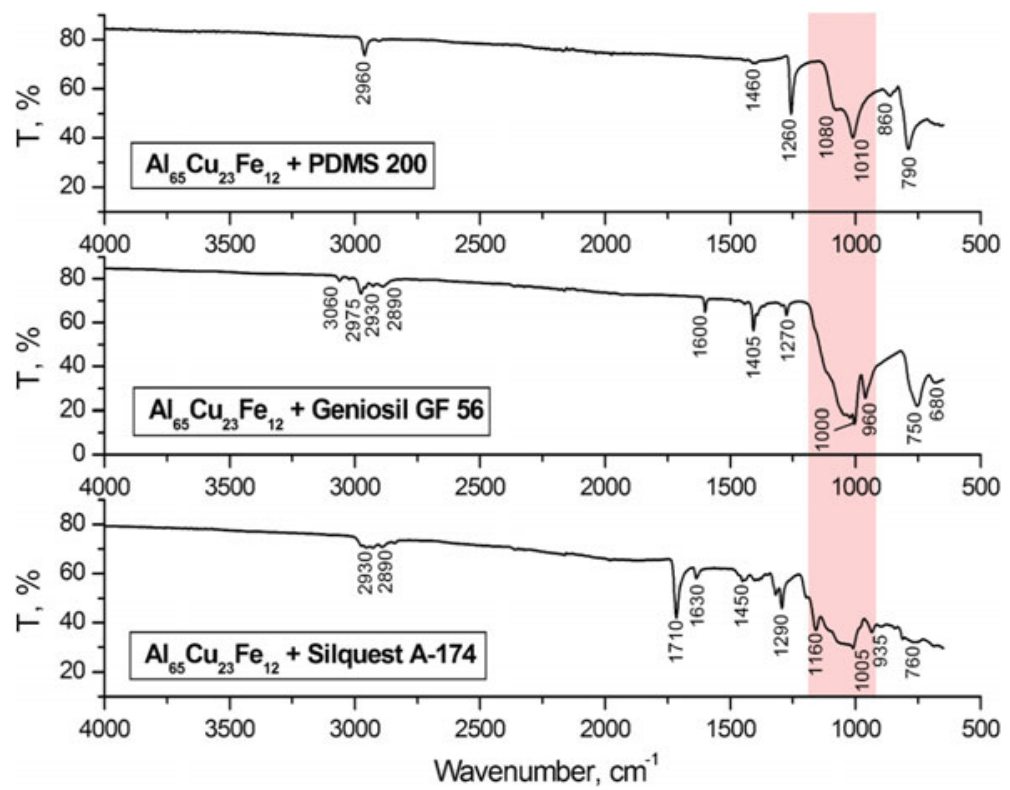

Fig. 3 FTIR spectra of the $\mathrm{Al}_{65} \mathrm{Cu}_{23} \mathrm{Fe}_{12}$ quasicrystalline powders treated with triethoxyvinylsilane Geniosil GF 56, gamma-methacryloxypropyltrimethoxysilane Silquest A-174, and polydimethylsiloxane PDMS 200

quasicrystals. In case of silane PDMS 200, the strong peaks of silane are observed and their intensity remains almost unchanged. Moreover, in contrast to PDMS200 the Geniosil GF 56 and Silquest A174 silanes do form the suspension of the quasicrystalline particles and thin film on the particle surface. Finally, Geniosil GF 56 as the strongest agent was used further in the composite synthesis. 
Figure 4 shows that due to the high shear stress in the extrusion machine the aggregated particles are destructed and the homogenization is completed by 12-15 min. Increasing the viscosity of the melt allows one to manage the processes of destruction of the aggregated particles and further homogenization of the filled polymer. The melt flow of the concentrates filled with the quasicrystals is slightly reduced by $12-15 \%$ with the increase of filler concentration up to $40 \mathrm{wt} \%$. The differences in the melt flow of the concentrates based on icosahedral $\mathrm{Al}_{65} \mathrm{Cu}_{23} \mathrm{Fe}_{12}$ phase and a decagonal $\mathrm{Al}_{73} \mathrm{Cu}_{11} \mathrm{Cr}_{16}$ phase having a different shape of the particles, is statistically insignificant, when the particles are less than $3 \mu \mathrm{m}$ in size.

As it seen from the Table 1 the filling with quasicrystals results in the increase of stiffness and almost does not affect tensile strength for PPS and PSU. One can find no influence of quasicrystals' nature-both icosahedral and decagonal intermetallics return the same shift of the properties. Both for PPS and PSU Brinell hardness rises from about $130 \mathrm{~N} / \mathrm{mm}^{2}$ for pure polymers to about $160 \mathrm{~N} / \mathrm{mm}^{2}$ for the composites containing $20 \mathrm{w} . \%$ of quasicrystals, that reflects the modest.

Table 1 increase of yield strength. In general, this tendency reflects insufficient binding of the matrix and the filler and does not give promising perspective for the structural applications of the composites. The tribological applications, nevertheless, may still be considered and studied in future.

The measurements reveal the increase of thermal diffusivity from $0.132 \mathrm{~mm}^{2} / \mathrm{s}$ for pure PPS to $0.154 \mathrm{~mm}^{2} / \mathrm{s}$ for the composite containing $20 \mathrm{w} . \%$ of filler regardless the nature of quasicrystals (from $0.115 \mathrm{~mm}^{2} / \mathrm{s}$ for pure PSU to $0.137 \mathrm{~mm}^{2} / \mathrm{s}$ for the composite with $20 \mathrm{w} . \%$ of filler). These data as well as the DSC measured data on heat capacity and density were used for the calculation of thermal conductivity. The increase of thermal conductivity for about $25 \%$ for PPS and for $32 \%$ for PSU was found which reflects the leading contribution of the density rise rather than heat capacity decrease.

The increment of thermal properties in combination with the expected low friction coefficient and surface energy points on the tribological applications for

Fig. 4 The uniform distribution of quasicrystalline particles in Evatane 28-05 polymer after 12 min of extrusion mixing

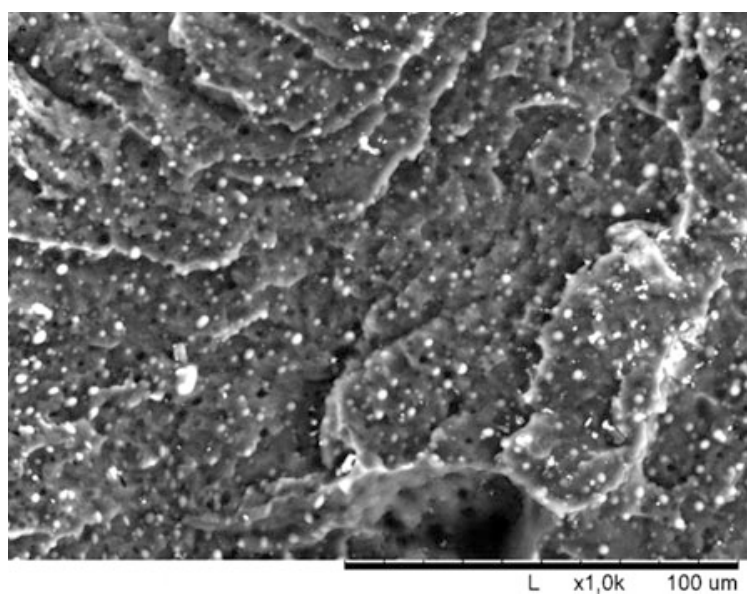


Table 1 Mechanical properties of the PPS and PSU at tension-based composites filled with quasicrystalline powders

\begin{tabular}{|c|c|c|c|c|c|c|c|}
\hline \multirow{2}{*}{\multicolumn{2}{|c|}{$\begin{array}{l}\text { QC } \\
\text { composite }\end{array}$}} & \multicolumn{3}{|c|}{$\mathrm{Al}_{65} \mathrm{Cu}_{23} \mathrm{Fe}_{12}$} & \multicolumn{3}{|c|}{$\mathrm{Al}_{73} \mathrm{Cu}_{11} \mathrm{Cr}_{16}$} \\
\hline & & \multirow{2}{*}{$\begin{array}{l}\sigma_{\mathrm{B}}(\mathrm{MPa}) \\
81.0 \pm 1.7\end{array}$} & \multirow{2}{*}{$\begin{array}{l}E(\mathrm{MPa}) \\
2894 \pm 33.8\end{array}$} & \multirow{2}{*}{$\begin{array}{l}\varepsilon(\%) \\
10.3 \pm 0.3\end{array}$} & \multirow{2}{*}{$\begin{array}{l}\sigma_{\mathrm{B}}(\mathrm{MPa}) \\
81.0 \pm 1.7\end{array}$} & \multirow{2}{*}{$\begin{array}{l}E(\mathrm{MPa}) \\
2894 \pm 33.8\end{array}$} & \multirow{2}{*}{$\begin{array}{l}\varepsilon(\%) \\
10.3 \pm 0.3\end{array}$} \\
\hline PPS & & & & & & & \\
\hline PSU & & $78.1 \pm 1.1$ & $2688 \pm 24.8$ & $4.3 \pm 0.2$ & $78.1 \pm 1.1$ & $2688 \pm 24.8$ & $4.3 \pm 0.2$ \\
\hline PPS & \multirow{2}{*}{$\begin{array}{l}+1 \mathrm{w} . \% \\
\text { QC }\end{array}$} & $81.2 \pm 1.3$ & $2904 \pm 10.1$ & $10.5 \pm 0.6$ & $81.4 \pm 1.1$ & $2914 \pm 25.7$ & $10.2 \pm 0.1$ \\
\hline PSU & & $77.5 \pm 0.7$ & $2728 \pm 30.5$ & $4.2 \pm 0.2$ & $77.8 \pm 0.9$ & $2732 \pm 24.8$ & $4.2 \pm 0.3$ \\
\hline PPS & \multirow{2}{*}{$\begin{array}{l}+2 \text { w. } \% \\
\text { QC }\end{array}$} & $81.3 \pm 0.8$ & $2944 \pm 4.9$ & $10.2 \pm 0.4$ & $81.6 \pm 1.2$ & $2948 \pm 16$ & $10.0 \pm 0.2$ \\
\hline PSU & & $77.3 \pm 1.7$ & $2758 \pm 20.4$ & $4.1 \pm 0.3$ & $77.6 \pm 1.4$ & $2746 \pm 13.5$ & $4.0 \pm 0.4$ \\
\hline PPS & \multirow{2}{*}{$\begin{array}{l}+5 \mathrm{w} . \% \\
\text { QC }\end{array}$} & $82.1 \pm 0.7$ & $3114 \pm 15$ & $9.9 \pm 0.5$ & $81.9 \pm 0.5$ & $3112 \pm 17.2$ & $9.6 \pm 0.5$ \\
\hline PSU & & $77.6 \pm 2.4$ & $2812 \pm 31.2$ & $3.5 \pm 0.3$ & $76.9 \pm 1.6$ & $2830 \pm 22.8$ & $3.4 \pm 0.2$ \\
\hline PPS & \multirow{2}{*}{$\begin{array}{l}+10 \text { w. } \% \\
\text { QC }\end{array}$} & $80.9 \pm 0.6$ & $3144 \pm 22.4$ & $6.5 \pm 0.3$ & $80.8 \pm 1.0$ & $3148 \pm 24$ & $6.6 \pm 0.2$ \\
\hline PSU & & $74.0 \pm 2.7$ & $2998 \pm 34.3$ & $3.1 \pm 0.3$ & $72.9 \pm 2.6$ & $2996 \pm 20.6$ & $3.2 \pm 0.4$ \\
\hline PPS & \multirow{2}{*}{$\begin{array}{l}+20 \text { w. } \% \\
\text { QC }\end{array}$} & $81.7 \pm 0.5$ & $3414 \pm 20.6$ & $6.3 \pm 0.3$ & $81.3 \pm 0.3$ & $3424 \pm 22.5$ & $6.0 \pm 0.7$ \\
\hline PSU & & $66.5 \pm 3.5$ & $3214 \pm 35.5$ & $2.5 \pm 0.4$ & $67.3 \pm 3.3$ & $3242 \pm 35.4$ & $2.6 \pm 0.3$ \\
\hline
\end{tabular}

composite bearings or other high demanding movable mechanical parts. Additionally to higher hardness the facilitated heat release from the tribological contact will reduce the local overheating and by this will protect the matrix against temperature softening and degradation.

\section{Conclusions}

The technology for the production of quasicrystalline powder fillers and their introduction to the polymer matrix to finally gain the composite material was developed. The production technology combines the mechanical alloying of powder metals and subsequent heat treatment of the alloyed powders in an inert atmosphere. The technology for the introduction of quasicrystalline to the polymer matrix presumes the treatment with the optimal silane and high energy extrusion mixing at appropriate time in order to reach the homogeneous distribution of the powder filler. The agglomerates obtained at the production stage are crushed and the powder particles of $3 \mu \mathrm{m}$ size are uniformly distributing in the polymer matrix. The rheological characteristics of the polymers filled with modified icosahedral $\mathrm{Al}_{65} \mathrm{Cu}_{23} \mathrm{Fe}_{12}$ and decagonal $\mathrm{Al}_{73} \mathrm{Cu}_{11} \mathrm{Cr}_{16}$ quasicrystals show that the melt flow of the concentrates depends on the particle size and does not depend on particle' shape.

The resulting concentrates, which are based on highly filled thermoplastic polymers and silane-treated quasicrystalline powders, make possible to synthesize the composite materials based on polyolefin material like PSU and PPS. The mechanical properties of the composites show almost no enhancement as a result of filling. The thermal diffusivity and conductivity, however, rise with the 
quasicrystals' content what in combination with the hardness increase opens the field of tribological applications like bearings or guiding parts.

It is believed that possible areas for application of these materials are also the composite coatings of the pipes with the reduced rate of deposition of organic deposits due to a low surface energy of the reinforcing quasicrystalline phase, which is comparable to that of pure polymers.

Acknowledgements Research are carried out with the financial support of the state represented by the Ministry of Education and Science of the Russian Federation. Agreement (contract) no. 14.578.21.0003 05.07.2014. Unique project Identifier: RFMEFI157814X0003.

\section{References}

1. Shaitura, S., Enaleeva, A.A.: Fabrication of quasicrystalline coatings: a review. Cryst Rep 52, 945-952 (2007)

2. Samavat, F., Tavakoli, M.H., Habibi, S., Jaleh, B., Ahmad, P.T.: Quasicrystals. Open J. Phys. Chem. 2, 7-14 (2012)

3. Dubois, J.M., Kang, S.S., Perrot, A.: Towards applications of quasicrystals. Mater. Sci. Eng. A. 179(180), 122-126 (1994)

4. Vekilov, Y.K., Chernikov, M.A.: Quasicrystals. Phys. Usp. 53, 537-560 (2010)

5. Koester, U., Liu, W., Hertzberg, H., Michel, M.: Mechanical properties of quasicrystalline and crystalline phases in Al-Cu-Fe alloys. J. Non Cryst. Solids 153(154), 446-452 (1993)

6. Jenks, C.J., Thiel, P.A.: Surface properties of quasicrystals. MRS Bull. 22(11), 55-58 (1997)

7. Huttunen-Saarivirta, E.: Microstructure, fabrication and properties of quasicrystalline $\mathrm{Al}-\mathrm{Cu}-$ Fe alloys: a review. J Alloys Comp. 363, 150-174 (2004)

8. Thiel, A., Dubois, J.M.: Quasicrystals. Reaching maturity for technological applications. Mater. Today 2(3), 3-7 (1999)

9. Roy, M.: Formation and magnetic properties of mechanically alloyed $\mathrm{Al}_{65} \mathrm{Cu}_{20} \mathrm{Fe}_{15}$ quasicrystal. J. Magn. Magn. Mater. 302:52-55 (2006)

10. Maciá, E.: Optimizing the thermoelectric efficiency of icosahedral quasicrystals and related complex alloys. Phys. Rev. B 80, 205103 (2009)

11. Takagiwa, Y., Kamimura, T., Hosoi, S., Okada, J.T., Kimura, K.: Thermoelectric properties of polygrained icosahedral $\mathrm{Al}_{71-}{ }_{x} \mathrm{Ga}_{x} \mathrm{Pd}_{20} \mathrm{Mn}_{9}(x=0,2,3,4)$ quasicrystals. J. Appl. Phys. 104, 073721 (2008)

12. Dubois, J.M.: New prospects from potential applications of quasicrystalline materials. Mater. Sci. Eng. A 294-296, 4-9 (2000)

13. Zou, Y., Kuczera, P., Sologubenko, A., Sumigawa, T., Kitamura, T., Steurer, W., Spolenak, R.: Superior room-temperature ductility of typicallybrittle quasicrystals at small sizes. Nat. Commun. 7, 12261, DOI:10.1038/ncomms12261, www.nature.com/naturecommunications

14. Mordyuk, B.N., Prokopenko, G.I., Milman, Y.V., Iefimov, M.O., Grinkevych, K.E., Sameljuk, A.V., Tkachenko, I.V.: Wear assessment of composite surface layers in Al-6 Mg alloy reinforced with AlCuFe quasicrystalline particles: effects of particle size, microstructure and hardness. Wear 319, 84-95 (2014)

15. Lityńska-Dobrzyńska, L., Dutkiewicz, J., Stan-Głowińska, K., Wajda, W., Dembinski, L., Langlade, C., Coddet, C.: Characterization of aluminium matrix composites reinforced by $\mathrm{Al}-\mathrm{Cu}-\mathrm{Fe}$ quasicrystalline particles. J. Alloys Comp. 643, S114-S118 (2015) 
16. Ali, F., Scudino, S., Anwar, M.S., Shahid, R.N., Srivastava, V.C., Uhlenwinkel, V., Stoica, M., Vaughan, G., Eckert, J.: Al-based metal matrix composites reinforced with Al-Cu-Fe quasicrystalline particles: strengthening by interfacial reaction. J. Alloys Comp. 607, 274-279 (2014)

17. Laplanche, G., Joulain, A., Bonneville, J., Schaller, R., El Kabir, T.: Microstructures and mechanical properties of Al-base composite materials reinforced by $\mathrm{Al}-\mathrm{Cu}-\mathrm{Fe}$ particles. J. Alloys Comp. 493, 453-460 (2010)

18. Qi, Y.H., Zhang, Z.P., Hei, Z.K., Dong, C.: The microstructure analysis of Al-Cu-Cr phases in $\mathrm{Al}_{65} \mathrm{Cu}_{20} \mathrm{Cr}_{15}$ quasicrystalline particles/Al base composites. J. Alloys Comp. 285, 221-228 (1999)

19. Tsai, A.P., Aoki, K., Inoue, A., Masumoto, T.: Synthesis of stable quasicrystalline particle-dispersed Al base composite alloys. J. Mater. Res. 8, 5-7 (1993)

20. Kaloshkin, S.D., Tcherdyntsev, V.V., Laptev, A.I., Stepashkin, A.A., Afonina, E.A., Pomadchik, A.L., Bugakov, V.I.: Structure and mechanical properties of mechanically alloyed Al/Al-Cu-Fe composites. J. Mater. Sci. 39, 5399-5402 (2004)

21. Kaloshkin, S.D., Tcherdyntsev, V.V., Stepashkin, A.A., Gulbin, V.N., Jalnin, B.V., Laptev, A.I., Obrucheva, E.V., Danilov, V.D.: Mechanical alloying of metal matrix composites reinforced by quasicrystals. J. Metast. Nanocr. Mater. 24-25, 113-116 (2005)

22. Tang, F., Anderson, I.E., Biner, S.B.: Microstructures and mechanical properties of pure Al matrix composites reinforced by Al-Cu-Fe alloy particles. Mater. Sci. Eng. A 363, 20-29 (2003)

23. Bloom, P.D., Baikerikar, K.G., Anderegg, J.W., Sheares, V.V.: Fabrication and wear resistance of $\mathrm{Al}-\mathrm{Cu}-\mathrm{Fe}$ quasicrystal-epoxy composite materials. Mater. Sci. Eng. A 360, 4657 (2003)

24. Bloom, P.D., Baikerikar, K.G., Otaigbe, J.U., Sheares, V.V.: Development of novel polymer/quasicrystal composite materials. Mater. Sci. Eng. A 294-296, 156-159 (2000)

25. Anderson, B.C., Bloom, P.D., Baikerikar, K.G., Sheares, V.V., Mallapragada, S.K.: Al-Cu$\mathrm{Fe}$ quasicrystal/ultra-high molecular weight polyethylene composites as biomaterials for acetabular cup prosthetics. Biomaterials 23, 1761-1768 (2002)

26. Kenzari, S., Bonina, D., Dubois, J.M., Fournée, V.: Quasicrystal-polymer composites for selective laser sintering technology. Mater. Design 35, 691-695 (2012)

27. Kaloshkin, S.D., Vandi, L.J., Tcherdyntsev, V.V., Shelekhov, E.V., Danilov, V.D.: Multi-scaled polymer-based composite materials synthesized by mechanical alloying. J. Alloys Comp. 483, 195-199 (2009)

Open Access This chapter is licensed under the terms of the Creative Commons Attribution 4.0 International License (http://creativecommons.org/licenses/by/4.0/), which permits use, sharing, adaptation, distribution and reproduction in any medium or format, as long as you give appropriate credit to the original author(s) and the source, provide a link to the Creative Commons license and indicate if changes were made.

The images or other third party material in this chapter are included in the chapter's Creative Commons license, unless indicated otherwise in a credit line to the material. If material is not included in the chapter's Creative Commons license and your intended use is not permitted by statutory regulation or exceeds the permitted use, you will need to obtain permission directly from the copyright holder.

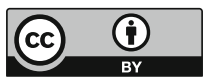

